Shin Freedman

\title{
Have librarians crossed the border of faculty sanctum of the academy? A personal journey of breaking barriers
}

Each spring at my institution, faculty from each discipline invest in evaluating their students to nominate them for "the best of" categories. Should the selection criteria be based on the GPA score, character traits, service recognition, overcoming adverse life situations, or unusual but worthy aspirations? What would be the most appropriate selection criteria? Similarly, academic deans from each college get together to select the best faculty in teaching, scholarship, advising, and service areas. Other nomination activities culminate in rewards ceremonies throughout the year. Most of all, the graduation commencement ceremony will be highlighted by the celebration of the award recipients from students and faculty. With admiration from the audience, including the students, faculty, administration and parents, the awardees march onto the graduation platform purposefully and proudly on that day.

I have been thinking about this for a while. Are librarians recognized as distinguished librarians of the year at our respective institutions or in the library? Does the commencement ceremony include and recognize librarians' contributions in public? My curiosity led me to reflect on this struggle in my mind in the era of diversity, inclusion, equity, and social justice.

This narrative is about my struggle for ten years at my institution to understand where I fit in from the perspective of scholarship and research. I am an academic librarian, researcher, scholar, and lecturer. When professional development funding opportunities arose, in my earlier days, I saw that librarians were not part of the eligible group on campus. My teaching faculty colleagues comforted me by saying that when we say faculty, of course, we meant, faculty and librarians. It never felt comfortable. I questioned myself by asking is this opportunity for me, as well? Or is it just for faculty only. My lived experience was that the second is true. Unless the application calls for librarians explicitly, it is meant to be for faculty only. Only I did not know that then.

Every springtime, there is call for nominations for a Distinguished Faculty Award (DFA). What do they mean by distinguished? The dictionary defines the word as successful and commanding great respect. Faculty is understood but may have only been implied as strictly

Shin Freedman is head of Scholarly Resources and Collections at the Framingham State University Whittemore Library, email: sfreedman@framingham.edu 
for teaching faculty members. The DFA was awarded to one faculty per year, but later the award category expanded gradually into four options: teaching, scholarship/research, creative works, advising, and service. The DFA process includes nominations by the university community starting in early March each year and nominations are submitted to the office of the provost. At some point, at the deans' meeting, the final selection for each category happens and the announcement is made in April.

I have nominated teaching faculty colleagues, and they all were confirmed as recipients of the award. Along the way, I encountered unexpected confessions and sad stories from colleagues over the nomination process as well as promotion and post-tenure decisions. I asked myself why my colleagues shared their private stories with me. It appears that they seemed touched by my work in support of fellow members of the community. If I may be so presumptuous, they may have felt the need when they were in need.

For those who believe that faculty means faculty and librarians, I realized that the words and their interpretation was not good enough. The terminology needed to be codified. If the nomination or application is intended for faculty and librarians, it must say so to be clear. Without such clarification, librarians suffer wondering whether we are eligible to receive awards, because we know deep in our hearts that we are not part of that group.

My personal journey to the DFA started a long time ago. I was nominated for the award by my students and faculty colleagues. Although at the time of my first nomination, there was implicit eligibility, I did not know that I was not eligible. The word faculty of course meant faculty/librarians, I assumed. However, the award was for faculty members only, despite my kind teaching faculty's consolation.

Fast forward several years, even before the pandemic impact on campuses around the world, a group of colleagues and myself challenged the language and its implication for the existing DFA eligibility, which resulted in adding the word librarian next to faculty in the language of the DFA. Probably no one noticed the difference but me. Subsequently, I was officially nominated for the DFA in the scholarship/research category. In the following year, I was nominated again for the same category of scholarship. Disappointingly, but perhaps predictably, I was not selected.

As I reflect on my experiences, several questions cross my mind. Have I ever crossed the border of sacred scholarship in academia? Can librarians, often on the margins of academe, be nominated and subsequently selected as a distinguished faculty/librarian of the year? I have passed many nomination hurdles over the last ten years. The only barrier left seemed to be the selection process. I may never know what happened other than that there are other faculty who are more deserving of the distinction. Trying hard and harder year after year does not seem make any difference, despite the increased number of citations, downloads, bibliometric counts, readership worldwide, and impact scores on my research and scholarship.

I wonder whether there is any room in the faculty culture to recognize academic librarians' scholarship. It should not be so different to evaluate and judge one's scholarship in terms of research outcomes, impact, and influence on readers whether using the Becker model or whatever the scholarship model may be. There should be a clear way to measure one's research output and outcomes. Please don't tell us it's not clear because teaching faculty do not know how to evaluate librarians' research. In any case, I am coming to terms with the fact that my scholarship accomplishments at my current institution may never be recognized. 
I am also pondering what more needs to be done to be selected as an equally qualified nominee beyond my published monographs, book chapters, and edited books; serving as an editorial reviewer; presenting posters, conference speeches, webinars in regional, statewide, national and international conferences and symposia; as well as receiving institution wide grants for ten consecutive years and prestigious external grants, including the U.S. Fulbright, a national fellowship from Institute of Museum and Library Services. What more could I have achieved as a librarian?

Irrespective of what we as librarians are capable of, or have demonstrated, the world outside of the library seems to regard us in one way: you can't be a researcher or a scholar because you're a librarian. You're a service provider. My faculty colleagues told me that they truly don't see librarians as researchers. Do we need to correct these assumptions and share the space in this conversation?

Please don't look at me as an individual. As an academic librarian who is also a woman of color with an immigrant background, I do have multiple identities beyond being an academic librarian. Please look at the accomplishments of my scholarship and research. Look at the influence and impact of my citations and readership around the world. What are we capable of doing well? After all, what matters to librarians is being recognized for our legitimate professional identities and their outcomes on campus, region, national, and international levels. $\approx$ 